\title{
Effect of rofecoxib on colon chemical carcinogenesis at colonic anastomotic area in the rat
}

\author{
J. F. Noguera Aguilar, I. Amengual Antich ${ }^{1}$, J. M. Morón Canis², A. Plaza Martínez ${ }^{3}$ J. A. Martínez \\ Córcoles $^{4}$, C. Tortajada Collado ${ }^{5}$ and J. J. Pujol Tugores ${ }^{6}$
}

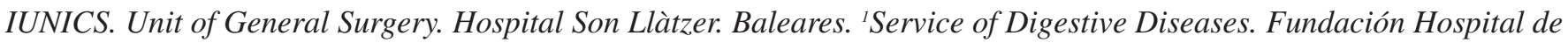
Manacor. Baleares. ${ }^{2}$ Service of General Surgery. Hospital Son Dureta. Baleares. ${ }^{3}$ Service of Vascular Surgery. Hospital Dr. Peset. Valencia. ${ }^{4}$ Service of General Surgery. Hospital Son Dureta. Baleares. ${ }^{5}$ Infirmary. Hospital Son Dureta. Baleares. ${ }^{6}$ Unit of General Surgery. Hospital Son Llàtzer. Baleares, Spain

\begin{abstract}
Aim: to investigate the effect of the selective cyclooxygenase-2 (COX-2) inhibitor rofecoxib on the incidence of perianastomotic colonic tumors in a model of chemical carcinogenesis in the rat.

Experimental design: experimental study with 45 male Sprague-Dawley rats randomly assigned to one of three groups: control $(n=15)$ with colocolic anastomosis and chemical carcinogenesis with 1-2 dimethylhydrazine (1-2 DMH); rofecoxib $0.0027 \%(\mathrm{n}=15)$ with colonic anastomosis, chemical carcinogenesis and the addition of dietary rofecoxib at doses of 27 parts per million (ppm), and rofecoxib $0.0058 \%(\mathrm{n}=15)$ with colonic anastomosis, chemical carcinogenesis and the addition of dietary rofecoxib at doses of $58 \mathrm{ppm}$. Carcinogenic induction was performed with 1-2 DMH at a weekly dose of $25 \mathrm{mg} / \mathrm{kg}$ of weight for 18 weeks, and colonic tumors induced were analyzed in postoperative week 20. The main parameter evaluated was the percentage of colonic neoplastic tissue, which relates tumor surface area to the colon's surface area.

Results: rofecoxib at doses of $2.5 \mathrm{mg} / \mathrm{kg}$ or $0.0058 \mathrm{ppm} \mathrm{sig-}$ nificantly reduced chemical colon carcinogenesis in rats, both in the perianastomotic area and the rest of the colon $(p<0.01)$. In the extra-anastomotic area, rofecoxib at doses of $2.5 \mathrm{mg} / \mathrm{kg}$ has significantly greater inhibitory effect than rofecoxib in doses of $1.2 \mathrm{mg} / \mathrm{kg}$ or $0.0027 \mathrm{ppm}(\mathrm{p}<0.005)$.

Conclusions: rofecoxib causes a reduction in chemical colon carcinogenesis in rats. This effect is sustained in the perianastomotic area, and the investigation of its role in operated colorectal cancer with risk of locoregional recurrence may therefore be of interest.
\end{abstract}

Key words: Rofecoxib. Colorectal cancer. Rat. Adenocarcinoma. Cyclooxigenase.

This study was partly supported by a grant from Merck-Sharp \& Dohme.

Recibido: 28-09-04.

Aceptado: 03-01-05.

Correspondencia: José Francisco Noguera Aguilar. Servicio de Cirugía General. Hospital Son Llàtzer. Ctra. de Manacor, km. 4. 07198 Son Ferriol. Palma de Mallorca. e-mail: jnoguera@hsll.es
Noguera Aguilar JF, Morón Canis JM, Amengual Antich I, Plaza Martínez A, Pujol Tugores JJ. Effect of rofecoxib on colon chemical carcinogenesis at colonic anastomotic area in the rat. Rev Esp Enferm Dig 2005; 97: 405-415.

\section{INTRODUCTION}

Colorectal cancer is the most common digestive cancer in Western Europe and the United States (1), and the second leading cause of death in the Western world (2). In our country it has an incidence of 20-30 cases per 100,000 inhabitants per year, and is responsible for $20 \%$ of deaths caused by malignancies $(3,4)$. Colorectal cancer (CRC) has an overall 5-year survival rate of $60 \%$ (5).

There are basically two strategies to improve the survival of patients with CRC: early detection of the disease and premalignant lesions, and chemoprevention. Early treatment of premalignant or early-stage malignant lesions decreases the incidence and mortality of CRC (6-8). Various agents have been proposed as potential chemopreventive agents for $\mathrm{CRC}$, including drugs such as COX-2 inhibitors.

Cyclooxygenase (COX) is the enzyme catalyzing the first steps in the synthesis of prostaglandins from arachidonic acid. There are two COX isoforms, which are structurally similar and catalyze the same chemical reaction, but with different action sites and times: COX-1 is constitutional, and is expressed always by all tissues; COX-2 is in turn inducible by various stimuli generally associated with inflammation (both acute and chronic) (9-11).

The activity of COX-2 appears to be related to neoplastic proliferation in aberrant colonic crypts by inhibiting apoptosis or programmed death in tumor cells, and by favoring tumor expansion upon the induction of tumor angiogenesis (12). Overexpression of COX-2 has been reported in colon tumors; therefore, COX-2-specific 
inhibitors may be used as preventive agents. Numerous studies have isolated the enzyme cyclooxigenase- 2 from the stroma of adenomas, and the stroma and epithelium of CRCs (13-15), while some authors have even related the extent of COX-2 expression to CRC survival rates (16).

Three COX-2 inhibitors are currently available -celecoxib, parecoxib and rofecoxib. Rofecoxib (Vioxx ${ }^{\circledR}, \mathrm{MK}-$ 0966) possesses a much greater inhibitory effect than celecoxib, and its inhibition of COX-1 is virtually nil (17); however, its availability has been recently discontinued.

The aim of the present study was to assess whether rofecoxib has an inhibitory effect on carcinogenesis as induced in a perianastomotic area. As a secondary objective, a potential dose-dependent effect will be assessed by measuring the two drug concentrations in the diet of animals.

Chemical carcinogenesis will be induced to determine the effect of rofecoxib on the development of induced tumors. Colon carcinogenesis induced by 1-2 dimethylhydrazine (1-2 DMH) induces the formation of aberrant crypt foci in the intestinal epithelium and promotes carcinogenesis after induction. This dysplastic epithelium overexpresses COX-2, and COX-2-specific inhibitors may have a suppressive effect on the colonic tumors induced.

The creation of a colonic anastomosis predisposes to continuous tissue promotion and regeneration, and such a site is prone to the formation of aberrant crypts, dysplasia, adenomas, and adenocarcinomas. The experimental model used simulates the oncogenic process in humans. Rats were operated on to create a colonic anastomosis, and then chemical carcinogenesis was induced to determine the protective effect of rofecoxib on tumor development in the perianastomotic area.

\section{MATERIALS AND METHODS}

Forty-five male Sprague-Dawley rats (Criffa, Spain) with a mean weight of $240 \mathrm{~g}$ (range 180-300 g) were used in the study. Rats were distributed into three groups: control $(n=15)$, with the creation of a colocolic anastomosis and chemical carcinogenesis using 1-2 DMH; rofecoxib $0.0027 \%(\mathrm{n}=15)$, with a colonic anastomosis and chemical carcinogenesis identical to those in the previous group, and with the addition of dietary rofecoxib at a dose of $27 \mathrm{ppm}$, and rofecoxib $0.0058 \%(\mathrm{n}=15)$, with a colonic anastomosis, chemical carcinogenesis and the addition of dietary rofecoxib at doses of 58 ppm. The carcinogenic induction of colonic neoplasias was achieved with 1-2 DMH (Sigma-Aldrich, Spain).

\section{Dietary and environmental conditions}

Rats were housed in type III cages (Criffa, Spain), with two animals per cage. Environmental conditions at the animal storage area were: $12 \mathrm{~h} / 12 \mathrm{~h}$ light/dark cycle (light from 8:00 a.m.-8:00 p.m.); uniform temperature of
$22 \pm 2{ }^{\circ} \mathrm{C}$, and relative humidity of $60-70 \%$. Food provided was a supplemented maintenance diet including MK0966 and rofecoxib in doses of 0.0027 or $0.0058 \%$ (Purina Lab., USA).

The study complied with guidelines established by Royal Decree 223/1998 and European Directive $86 / 609 /$ EEC on the protection of animals used in experimentation.

\section{Anesthetic technique}

A solution of ketamine, atropine and diazepam was used (50, 10 and 40\%, respectively); it was administered intramuscularly at a dose of $4 \mathrm{ml} / \mathrm{kg}$.

\section{Surgical technique}

A midline laparotomy of 3-4 $\mathrm{cm}$ in length was performed in the lower part of the abdomen, with the site of colonic manipulation being identified at $4 \mathrm{~cm}$ from the anus. To create a colocolic anastomosis, a complete section of the colon was performed and the wound was then closed using 5/0 non-reabsorbable suture (polyvinyldifluorethylene, PVDF, Lorca-Marín, Spain). Eight stitches were placed at equal distances and the anastomosis was checked for intraoperative watertightness by the endoanal route.

\section{Carcinogenic induction and administration of rofecoxib}

After eight days in the postoperative period colonic tumors were induced with 1-2 DMH by administering 18 weekly subcutaneous injections at a weekly dose of $25 \mathrm{mg} / \mathrm{kg}$ of weight, and rofecoxib was administered orally, mixed with food, at the previously indicated concentrations of 27 or $58 \mathrm{ppm}$.

\section{Follow-up and sacrifice}

Animals were examined weekly, and special attention was paid to their weight, abdominal perimeter, presence and quality of stools, and presence of rectal bleeding. All animals were sacrificed in postoperative week 20 and the colon was examined for colonic tumors. Sacrifice was by anesthetic overdose, and a midline laparotomy was performed to search for the presence of extradigestive tumors or macroscopic tumors in the small intestine. The entire colon was removed from the anus to the cecum, also including $1 \mathrm{~cm}$ of the terminal small intestine. Pieces were fixed in a $10 \%$ formaldehyde solution for histologic examination. 


\section{Examination of colonic tumors}

The entire large intestine of each animal was examined to determine three parameters: number of tumors, tumor surface area, and percentage of tumor surface area (percentage of colon area occupied by tumor tissue). The perianastomotic area including one centimeter on each side of the anastomosis suture line was separated. Percentage of tumor was determined by estimating total colon surface area versus tumor surface area in the colon. A histologic study of colonic pieces also determined histologic type, histologic grade, tumor invasion, and lymph node involvement for each individual lesion.

\section{Statistical analysis}

Study data were analyzed using the SPSS and G-Stat software programs, and statistical analyses were performed using one-factor ANOVA models (Scheffé and Bonferroni test) and Chi squared tables.

\section{RESULTS}

\section{Mortality}

The overall mortality rate in the study was $4.44 \%$ (2 out of 45 animals). There was one postoperative death in the control group, which was replaced by another animal as it occurred early in the study; another death occurred in the rofecoxib $0.0058 \%$ group that was not replaced, since this one occurred in the middle of the study; thus this group had a total of 14 valuable animals.

\section{Alterations in colonic transit}

No alterations occurred in gastrointestinal transit; a macroscopic study of the colon after sacrifice found no totally or partially stenosing neoplasms.

\section{Number of tumors}

A total of 56 colonic tumors were found in the 44 animals studied, with a mean of 1.27 colonic tumors per animal. Of these 56 tumors, 49 were malignant tumors (adenocarcinomas) and 7 were adenomas. The mean number of adenomas per animal was 0.16 , whereas the mean number of adenocarcinomas was 1.11. The distribution of these tumors is shown in table I. Differences between groups in the incidence of malignant and benign tumors were not significant.

With regard to the location of adenocarcinomas, most occurred in the perianastomotic area $(57.14 \%)$ (Table II). When the number of tumors in each area was compared
Table I. Drug-induced benign and malignant colonic tumors in the study groups

\begin{tabular}{lccc}
\hline & Adenoma & Adenocarcinoma & All \\
\hline Control & 3 & 18 & 21 \\
Rofecoxib & 0 & 18 & 18 \\
$0.0027 \%$ & & & \\
Rofecoxib & 4 & 13 & 17 \\
$0.0058 \%$ & & & \\
$\Sigma$ & 7 & 49 & 56 \\
\hline
\end{tabular}

Table II. Relationship between perianastomotic and extraanastomotic colon adenocarcinomas

\begin{tabular}{lcc}
\hline & Perianastomotic & Extra-anastomotic \\
\hline Control & 12 & 6 \\
Rofecoxib & 10 & 8 \\
$0.0027 \%$ & & \\
Rofecoxib & 6 & 7 \\
$0.0058 \%$ & & \\
$\Sigma$ & 28 & 21 \\
\hline
\end{tabular}

to the colon surface area in this region, it was found that 0.34 tumors $/ \mathrm{cm}^{2}$ occurred in the perianastomotic area, whereas 0.048 tumors $/ \mathrm{cm}^{2}$ were found in the rest of the colon.

\section{Microscopic tumor surface area}

Total colon tumor surface area for all animals included in the study was $22.78 \mathrm{~cm}^{2}$. Of this total area, $0.8 \mathrm{~cm}^{2}$ were benign tumors and the rest, $21.98 \mathrm{~cm}^{2}$, adenocarcinomas. Mean tumor surface area was similar in groups studied, with a value of $0.56 \pm 0.52 \mathrm{~cm}^{2}$ in the control group, $0.48 \pm 0.42$ in the low-dose rofecoxib group, and $0.44 \pm 0.52 \mathrm{~cm}^{2}$ in the high-dose rofecoxib group. Considering only anastomotic tumors, tumor surface area was moderate in the rofecoxib groups $(0.26 \pm 0.23$ for highdose rofecoxib and $0.22 \pm 0.19$ for low-dose rofecoxib) versus the control one $(0.46 \pm 0.35)$, with differences being non-significant. With respect to extra-anastomotic tumors, differences were subtle.

\section{Microscopic tumor percentage}

This parameter is the most reliable indicator of induced carcinogenesis, as it assesses the formation of glandular tissue with adenocarcinoma adjusted to the size of the colon in each animal. There were differences in animal weight and so in colon size, but the relationship between tumoral surface and total colon surface was the 
best parameter. In the control group, average weight at the beginning of the study was $294.6 \mathrm{~g}$ (range 210-320), while in $0.0027 \%$ rofecoxib was $225.6 \mathrm{~g}(170-265)$, and in $0.0058 \%$ rofecoxib was $298.7 \mathrm{~g}$ (250-350).

The percentage results for adenomas were practically negligible, since they accounted for only $0.15 \%$ of total colon surface area. Considering all colonic adenocarcinomas induced, we observed that the highest percentage was obtained in the control group $-4.83 \%(4.83 \pm 3.8)$ whereas it decreased in the group receiving $0.0027 \%$ doses of rofecoxib to $3.53 \%(3.53 \pm 2.6)$, and was practically negligible in the group receiving $0.0058 \%$ doses of rofecoxib, with a value of $0.033 \%(0.03 \pm 0.01)$. These differences were significant when the latter group was compared to the previous two groups $(\mathrm{p}<0.01$ and $\mathrm{p}<0.0001$, one-factor ANOVA, LSD and Scheffé test) (Fig. 1).

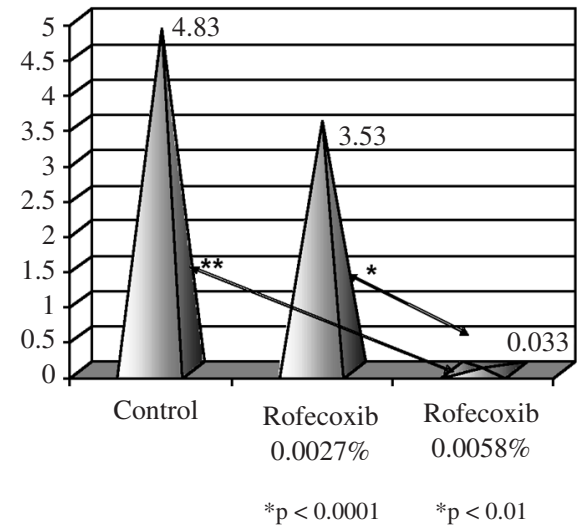

\section{$\square$ Percentaje \%}

Fig. 1.- Percentage of tumor tissue with adenocarcinoma in the whole colon.

Porcentaje de tejido tumoral con adenocarcinoma cólico en el colon global.

If we consider perianastomotic tumors, previously found differences remained, but a significant reduction was only achieved with rofecoxib at doses of $0.0058 \%$ ( $p$ $=0.0056$, one-factor ANOVA, LSD and Scheffé). Differences between rofecoxib in doses of $0.0027 \%$ and $0.0058 \%$ were similar to those found for the colon overall, but they had a value of $\mathrm{p}=0.054$ (Fig. 2).

When extra-anastomotic tumors were assessed, we found results similar to those obtained for the colon overall. Differences were significant for the rofecoxib $0.0058 \%$ group versus the control group and versus the rofecoxib $0.0027 \%$ group, with tumor percentages that were nearly negligible for the high-dose rofecoxib group $-0.029 \%(0.029 \pm 0.01)-$ versus percentages of 3.59 $(3.59 \pm 2.6)$ in the low-dose rofecoxib group and 2.68

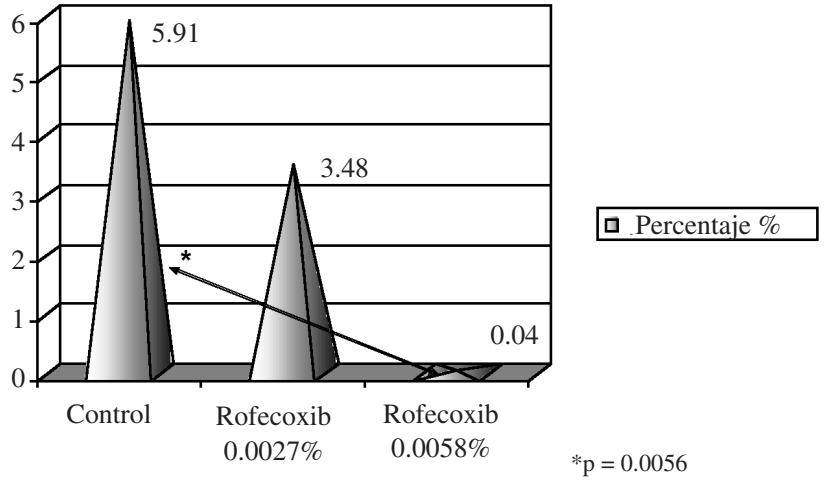

Fig. 2.- Percentage of tumor tissue with adenocarcinoma in the perianastomotic area.

Porcentaje de tejido tumoral con adenocarcinoma en el área perianastomótica.

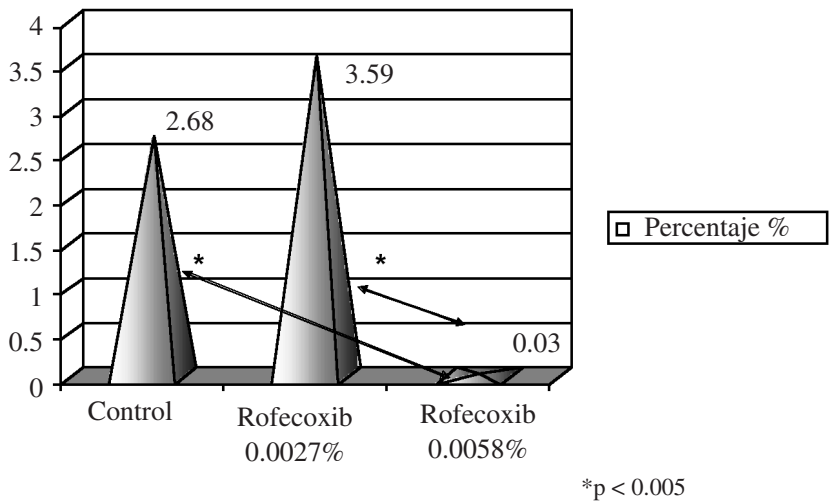

Fig. 3.- Percentage of tumor tissue with adenocarcinoma in the extraanastomotic colon.

Porcentaje de tejido tumoral con adenocarcinoma en el colon extraanastomótico.

$(2.68 \pm 1.5)$ in the control group $(\mathrm{p}=0.0043$, one-factor ANOVA, LSD and Scheffé) (Fig. 3).

\section{Histologic study}

Adenomas $(\mathrm{n}=7)$ accounted for $12.5 \%$ of tumors induced, and the remainder were adenocarcinomas $(87.5 \%$ of neoplasias). Adenocarcinomas were well differentiated in $26.53 \%$, moderately differentiated in $44.89 \%$, and poorly differentiated in $28.58 \%$ of cases. As for the degree of invasion in adenocarcinomas, most reached the submucosa $(57.14 \%)$ and $42.85 \%$ invaded beyond the submucosa. A total of 179 epicolic nodes (4.06 per rat) were isolated, 14 (7.8\%) of which contained micrometastases from adenocarcinoma. None of the differences between groups in these parameters was significant. 


\section{DISCUSSION}

The first evidence of a relationship between NSAIDs and colon cancer was obtained in an epidemiological study conducted by Kune in 1988 (18), where a lower incidence of CRC was observed in patients with inflammatory bowel disease who were chronic users of sulfasalazine.

More than 100 studies have been published that evaluate NSAIDs in the chemoprevention of drug-induced CRC in animal models, and over $85 \%$ of them show that NSAIDs reduce the incidence and multiplicity of these tumors $(19,20)$.

With regard to COX-2 selective inhibitors, the first evidence of their efficacy in animals is from studies conducted in Min (multiple intestinal neoplasia) mice, a transgenic mouse model with a dominant mutation in the APC (adenomatous colon polyposis) gene that is characterized by the development of multiple intestinal adenomas at an early age (21). In these rats, the administration of celecoxib causes a greater reduction in the number of adenomas versus piroxicam. The administration of rofecoxib also causes similar effects in these mice (21-23). The effects of COX-2 selective inhibitors have also been studied in rats exposed to azoxymethane, a potent colon carcinogen. In these models of drug-induced carcinogenesis aberrant foci of colon crypts were reduced by 40$49 \%$ when celecoxib was administered. Subsequent studies have confirmed significant reductions in the incidence of CRC and in its multiplicity in animals exposed to carcinogen and treated with celecoxib $(24,25)$. Most of these studies have been carried out with celecoxib, and there are few studies with rofecoxib, which has a 2-fold greater selectivity for COX-2 than celecoxib. Currently, proapoptotic mechanisms have been described for coxibs that may be COX-2-independent; thus the chemoprevention of colorectal cancer may depend on two ways -with and without COX dependence.

The compound MK-0966, rofecoxib, undergoes rapid absorption in rats and attains peak blood concentration 30 minutes after administration. Dose increases greater than $5 \mathrm{mg} / \mathrm{kg}$ do not result in increased plasma levels of the drug in the rat (26). It is primarily excreted in the bile, and metabolites derived from drug oxidation, glucuronoconjugation and reduction are not active in terms of cyclooxygenase- 1 or -2 inhibition (27). Doses used in this study, $0.0027 \mathrm{ppm}$ and $0.0058 \mathrm{ppm}$, are equivalent to $1.2 \mathrm{mg} / \mathrm{kg}$ and $2.5 \mathrm{mg} / \mathrm{kg}$ of weight. These drug concentrations are high if we compare them to the typical doses used for arthritis and acute pain, but according to clinical studies on pharmacokinetics, COX-2 inhibition is greater at higher doses, and the tolerability of high doses was acceptable (28). Last year MSD withdrew rofecoxib from the market in view of the results of the APPROVe study for the prevention of colic adenoma with rofecoxib regarding cardiovascular toxicity. However, further investigation of COX-2 inhibition in colorectal cancer is needed.
Recently, Becerra et al. (29) published their results from a study on metastatic colorectal cancer, where the addition of rofecoxib to conventional chemoterapy did not improve efficacy. Doses employed by Becerra et al. were $50 \mathrm{mg} /$ day, lower than those deemed useful in our study.

Most studies only refer to the number of colon tumors and omit parameters as important as tumor surface area and percentage. When not referring to aberrant crypts or dysplastic foci, but to induced colon tumors, we believe that microscopic tumor percentage should be evaluated, as it is the only parameter relating the amount of tumor tissue with the size of the colon being studied. The drug regimen used was $25 \mathrm{mg} / \mathrm{kg}$ of 1 $2 \mathrm{DMH}$ for 18 weeks with animal sacrifice in week 20, which has been shown to be more effective than other induction regimens using the same drug $(30,31)$, and to also shorten study duration.

In this study we found that rofecoxib in doses of 2.5 $\mathrm{mg} / \mathrm{kg}$ or $0.0058 \mathrm{ppm}$ significantly reduced the percentage of malignant colon tumors, i.e., drug-induced adenocarcinomas, versus the control group and versus rofecoxib in doses of $1.2 \mathrm{mg} / \mathrm{kg}$ or $0.0027 \mathrm{ppm}$. This result agrees with a study recently reported by Oshima et al., in which rofecoxib inhibited polyposis in APCdelta716 mice, which develop intestinal polyposis and secondary carcinomas $(23,32)$.

When perianastomotic and extra-anastomotic tumors were considered separately, we found that rofecoxib in doses of $2.5 \mathrm{mg} / \mathrm{kg}$ reduced the percentage of colon tumors versus the control group both in the anastomotic area and the rest of the colon, with statistically significant differences. Differences in the slowing down of drug-induced carcinogenesis between rofecoxib $1.2 \mathrm{mg} / \mathrm{kg}$ and rofecoxib $2.5 \mathrm{mg} / \mathrm{kg}$ were significant when all adenocarcinomas were considered and when only extra-anastomotic adenocarcinomas were considered. In the anastomotic area, the higher dose of rofecoxib was not found to be significantly better than the lower, $1.2 \mathrm{mg} / \mathrm{kg}$ dose $(\mathrm{p}=0.054)$.

We conclude that rofecoxib at doses of $2.5 \mathrm{mg} / \mathrm{kg}$ or 0,0058 ppm significantly reduces chemical colon carcinogenesis in rats, both in the perianastomotic area and in the rest of the colon. In the extra-anastomotic area, rofecoxib in doses of $2.5 \mathrm{mg} / \mathrm{kg}$ has a significantly greater inhibitory effect than rofecoxib in doses of $1.2 \mathrm{mg} / \mathrm{kg}$ or $0.0027 \mathrm{ppm}$.

Since rofecoxib delays chemical colon carcinogenesis in rats, we believe it a drug deserving assessment in future studies of colorectal cancer. This sustained effect in the perianastomotic area may have important implications for operated colorectal cancer with a risk for locoregional recurrence. We agree with Taxonera et al. (33) when they claim that the future of colorectal cancer therapy may lie in drug combinations, with coxibs taking part as agents that may have an antitumoral effect at different levels. 


\section{REFERENCES}

1. Arnaud JP, Schloegel M, Ollier JC, Adloff M. Colorectal cancer in patients over 80 years of age. Dis Colon Rectum 1991; 34: 896-8.

2. McGregor JR, Galloway DJ, McCulloch P, George WD. Anastomotic suture materials and implantation metastasis: an experimental study. Br J Surg 1989; 76 (4): 331-4.

3. Dominguez F, Riera JR, Junco P, Tojo S, Díaz-Faes M. Influencia en el pronóstico a corto plazo de la sobreexpresión de la proteina p53 en carcinomas colorrectales. Rev Esp Enferm Dig 1994; 86: 796-802.

4. García JC, Cugat E, Angás J, González FJ, Reverter JC, Lacy AM. Cáncer colorrectal: resultados de un protocolo de seguimiento. Cir Esp 1993; 53: 430-3.

5. García JA, Morcillo MA, Vázquez JL, Zaragoza C, Moltó M, Cámara J. Cáncer colorrectal en el anciano. Experiencia de los 5 primeros años en un Servicio de Cirugía de un hospital Comarcal. Cir Esp 1996; 60: 256-7.

6. Lieberman DA. Screening for colorectal cancer. Clin Cornerstone 2002; 4: 1-10.

7. Benamouzig R, Chaussade S. La chimioprevéntion du cancer colorectal. Presse Med 2002; 31: 124-8.

8. Sheehan KM, Sheahan K, O'Donoghue DP, MacSweeney F, Conroy RM, Fitzgerald DJ, et al. The relationship between cyclooxygenase-2 expression and colorectal cancer. JAMA 1999; 282: 1254-7.

9. Vane JR, Bakle YS, Botting RM. Cyclo-oxygenases 1 and 2. Annu Rev Pharmacol Toxicol 1998; 38: 97-120.

10. Brooks P, Emery P, Evans JF, Fenner H, Hawkey CJ, Patrono C, et al. Interpreting the clinical significance of the differential inhibition of cyclo-oxygenase-1 and cyclo-oxygenase-2. Rheumatology 1999; 38: 779-88.

11. Lipsky PE, Brooks P, Crofford LJ, DuBois R, Graham D, Simon LS, et al. Unressolved issues in the role of cyclooxygenase-2 in normal physiologic processes and disease. Arch Intern Med 2000; 160: 913-20.

12. Williams CS, Mann M, DuBois R. The role of cyclo-oxygenases in inflammation, cancer and development. Oncogene 1999; 18: 7908-16.

13. DuBois RN, Radhika A, Reddy BS, Entingh AJ. Increased cyclooxygenase-2 levels in carcinogen-induced rat colonic tumors. Gastroenterology 1996; 110: 1259-2.

14. Bamba H, Ota S, Kato A, Adachi A, Itoyama S, Matsuzaki F. High expression of cyclooxygenase-2 in macrophages of human colonic adenoma. Int J Cancer 1999; 83: 470-5.

15. Reddy BS, Yoshinobu Y, Lubet R, Steele V, Kelloff G, Paulson S, et al. Chemoprevention of colon cancer by specific cyclooxygenase-2 inhibitor, celecoxib, administered during different stages of carcinogenesis. Cancer Res 2000; 60: 293-7.

16. Kargman SL, O`Neill GP, Vickers PJ, Evans JF, Mancini JA, Jothy S. Expression of prostaglandin $\mathrm{G} / \mathrm{H}$ synthase -1 and -2 protein in human colon cancer. Cancer Res 1995; 55: 556-2559.

17. Chan CC, Boyce S, Brideau C, Charleson S, Cromlish W, Ethier D, et al. Rofecoxib [Vioxx, MK-0966; 4-(4'-methylsulfonylphenyl)-3phenyl-2-(5H)-furanone]: a potent and orally active cyclooxygenase2 inhibitor. Pharmacological and biochemical profiles. J Pharmacol Exp Ther 1999; 290: 551-60.
18. Kune GA, Kune S, Watson LF. Colorectal cancer risk, chronic illnesses, operations and medications.: case control results from the Melbourne Colorectal Cancer Study. Cancer Res 1988; 48: 4399404.

19. Wargovich MJ, Chen CD, Harris C. Inhibition of aberrant crypt growth by nonsteroidal anti-inflammatory agents an differentiation agents in the rat colon. Int J Cancer 1995; 60: 515-9.

20. Rao CV, Rivenson A, Simi B. Chemoprevention of colon carcinogenesis by sulindac, a nonsteroidal anti-inflammatory agent. Cancer Res 1995; 55: 1464-72.

21. Su LK, Kinzler KW, Vogelstein B, Preisinger AC, Moser AR, Luongo $\mathrm{C}$, et al. Multiple intestinal neoplasia caused by a mutation in the murine homolog of the Apc gene. Science 1992; 256: 668-70.

22. Jacoby RF, Seibert K, Cole CE, Kelloff G, Lubet RA. The cyclooxygenase- 2 inhibitor celecoxib is a potent preventive and therapeutic agent in the min mouse model of adenomatous polyposis. Cancer Res 2000; 60: 5040-4.

23. Oshima m, Murai N, Kargman S, Arguello M, Luk P, Kwong E, et al. Chemoprevention of intestinal polyposis in the Apc $\Delta 716$ mouse by rofecoxib, a specific cyclooxygenase-2 inhibitor. Cancer Res 2001; 61: 1733-40.

24. Reddy BS, Rao CV, Seibert K. Evaluation of cyclooxygenase-2 inhibitor for potential chemopreventive properties in colon carcinogenesis. Cancer Res 1996; 56: 4566-9.

25. Kawamori T, Rao CV, Seibert K, Reddy BS. Chemopreventive activity of celecoxib, a specific cyclooxygenase- 2 inhibitor, against colon carcinogenesis. Cancer Res 1998; 58: 409-12.

26. Halpin RA, Geer LA, Zhang KE, Marks TM, Dean DC, Jones AN, et al. The absorption, distribution, metabolism and excretion of rofecoxib, a potent and selective cyclooxygenase- 2 inhibitor, in rats and dogs. Drug Metab Dispos 2000; 28: 1244-54.

27. Nicoll-Griffith DA, Yergey JA, Trimble LA, Silva JM, Li C, Chauret $\mathrm{N}$, et al. Synthesis, characterization, and activity of metabolites derived from the cyclooxigenase-2 inhibitor rofecoxib (MK-0966, Vioxx). Bioorg Med Chem Lett 2000; 10: 2683-6.

28. Depre M, Ehrich E, Van Hecken A, De Lepeleire I, Dallob A, Wong $\mathrm{P}$, et al. Pharmacokinetics, COX-2 specificity, and tolerability of supratherapeutic doses of rofecoxib in humans. Eur J Clin Pharmacol 2000; 56: 167-74.

29. Becerra CR, Frenkel EP, Ashfaq R, Gaynor RB. Increased toxicity and lack of efficacy of rofecoxib in combination with chemotherapy for treatment of metastatic colorectal cancer: a phase II study. Int J Cancer 2003; 105: 868-72.

30. Noguera JF, Tortajada C, Morón JM, Plaza A, Amengual I, Pujol JJ. Experimental model for the study of perianastomotic recurrence in colorectal cancer. Rev Esp Enferm Dig 2002; 94: 131-4.

31. Noguera JF, Tortajada C, Zurita M, García JC, Álvarez C, Rial R. Nuevo régimen farmacológico para la inducción de tumores cólicos en ratas. Span J Surg Res 2000; 3: 33-5.

32. Evans JF. Rofecoxib (Vioxx), a specific cyclooxygenase-2 inhibitor, is chemopreventive in a mouse model of colon cancer. Am J Clin Oncol. 2003; 26: 62-5.

33. Taxonera C, Mendoza JL. Colorectal cancer and Coxibs. Rev Esp Enferm Dig 2004; 96: 673-7. 